\title{
Prevalence of Major Gastrointestinal Parasites in Small Scale Commercial Poultry Farms from Jimma Town, Southwest Ethiopia
}

\author{
Waktole Yadeta*, Takele Sori, Motuma Debelo, Bashahun G. Michael and Kula Jilo \\ School of Veterinary Medicine, College of Agriculture and Veterinary Medicine, Jimma University, Jimma, \\ Ethiopia
}

*Coresponding Author: Waktole Yadeta, School of Veterinary Medicine, College of Agriculture and veterinary Medicine, Jimma University, Jimma, Ethiopia

\begin{abstract}
A cross sectional study was conducted from November 2017 to March 2018 to determine prevalence and assess potential risk factors of major gastrointestinal parasites of poultry from Jimma town semi-intensive and intensive small scale commercial poultry farms, Ethiopia. A total of 384 fecal samples collected from randomly selected exotic chickens comprising of 110 Bovans brown and 274 Sasso T44 breeds were examined by floatation technique. The overall prevalence of major GIT parasites was 76\% (292 of the chickens were positive). Out of these, 36.97\%, 29.9\% and 3.39\% were nematodes, Eimeria species and cestodes respectively. The nematode species identified were Ascaridia galli (25.5\%), Heterakis gallinarum(9.4\%) and Capillaria species(1.3\%)while Cestode species were Railletina cesticillus(1.56\%), Railletina echinobothrida(1.04\%) and Davainea proglottina(0.78\%). $5.7 \%$ prevalence of mixed infections were also identified. There was a statistically significant difference $(p<0.05)$ in the prevalence between management system of chickens in which higher prevalence was observed in semi-intensive management $(80.3 \%)$ than intensive (70\%). There was also a statistically significant difference $(p<0.05)$ among age groups where higher prevalence was recorded in adults and growers $(85.6 \%$ and $83.3 \%)$ than chicks $(62.1 \%)$. But, There were no a statistically significant difference $(p>0.05)$ between sex and breeds. This study suggested high prevalence of major GIT parasites in Jimma town small scale commercial poultry farms. Thus, further studies to assess the impact of major gastrointestinal parasites on health and production performance of chickens should be conducted and appropriate control strategies need to be devised.
\end{abstract}

Keywords: Prevalence, Risk factors, chickens, gastrointestinal parasites, management System, Jimma, Ethiopia

\section{INTRODUCTION}

Poultry applies to a wide variety of several species and it refers to them weather they are alive or dressed. This term is used for chickens, turkeys, ducks, geese, swans, guinea fowl, pigeons, pea fowl, ostriches, pheasants, quails and other birds [1]. In Ethiopia, the word poultry is synonymous to chicken [2]. The Poultry industry occupies an important position in the provision of animal protein as meat and egg to human and generally plays a vital role in the national economy as a revenue provider [3]. Poultry production in Ethiopia is characterized into three major systems: these are Village or backyard poultry production system, Small scale commercial poultry production system and large scale Intensive Commercial poultry production system [4].

Small scale commercial poultry production system is newly emerging system in urban and per urban areas, where broilers, layers or dual purpose exotic breeds of 50 to 500 flock sizes chickens are kept using relatively modern management methods [5]. From a total of 56 million chickens estimated to be present in the country, $96.46 \%, 0.57$ percent and 2.97 were reported to be indigenous, hybrid and exotic breeds respectively [6]. Despite, the presence of large chicken population in Ethiopia, contribution to the national economy or benefit exploited is very limited due to diseases, predators and veterinary services [7]. Among parasitic diseases, Gastrointestinal parasites cause considerable damage and great economic losses to the poultry industry due to malnutrition, decreased feed conversion ratio, weight loss, lowered egg production, decreased resistance to diseases, exacerbating existing disease conditions and death in chickens worldwide [8]. These major gastrointestinal parasites that cause damages in poultry are Cestodes, Nematodes and protozoa (Eimeria species) [9]. 
The most important cestode species of poultry common in tropics are: Raillietinaechinobothrida, Raillietinatetragona, Raillietinacesticillus, Davaineaproglotina, Choanotaenia infundibulum, Amoebotaeniacuneata, Hymenolepis carioca and Hymenolepiscantaniana[10].Nematodes constitute the most important group of helminthes of poultry both in number of species and the extent of damage they cause, common ones are: Ascaridia galli, Heterakis gallinarum, Capillaria species, subulurabrumpti and syngamus trachea [11]. Eimeria species are protozoan parasites that has capable of causing the disease coccidiosis. Coccidiosis is one of a serious poultry gastrointestinal disease that infects the epithelial lining of the intestines and has greatest economic impact on poultry industries worldwide due to production losses and costs for treatment and prevention. Seven species of Eimeria(E.acervulina, E.brunetti, E.maxima, E.mitis, E. necatrix, E.praecoxand E.tenella) are recognized as the common causes of poultry coccidiosis [12].

Coccidiosis contributes to $8.4 \%$ loss in profit in large scale farms and $11.86 \%$ loss in profit in small scale farms in Ethiopia [13].

Worldwide there are few studies about diseases affecting poultry in small scale production system [14]. In Ethiopia currently there is little information that shows the prevalence and distribution of major gastrointestinal tract parasites. Yet, the studies conducted were limited in scope and focused on village or backyard production system which may not reflect the prevalence in small scale production system [15]. These were the rationale that initiated this research to be conducted at study area. Therefore, the objectives of this study were to determine the prevalence of major gastrointestinal parasites of small scale production system and assessing potential risk factors in the study area.

\section{Materials ANd Methods}

\subsection{Study Area}

The study was conducted from November 2017 to March 2018 to determine the prevalence and assess risk factors of major GIT parasites of poultry in Jimma town small scale commercial poultry farms, south western Ethiopia. Jimma town is located in Oromia region, south west of Ethiopia, at a physical distance of about $352 \mathrm{~km}$ from Addis Ababa, Capital of Ethiopia.. Geographically, Jimma is located at $7^{0} 13^{\prime}$ and $8^{0} 56^{\prime} \mathrm{N}$ latitude and $35^{\circ} 52^{\prime}$ and $37^{\circ} 37 \mathrm{E}$ longitude. The climatic condition of the area is 'Woynadega' with altitude ranging between 1720 to $2110 \mathrm{~m}$ above sea level and receives annual rainfall which ranges between 1200 to $2000 \mathrm{~mm}$. There are two rainy seasons, short rainy season (November to April) and long rainy season (July to October). The annual mean temperature ranges from about $12.1^{\circ} \mathrm{C}$ to $28^{\circ} \mathrm{C}$. Jimma zone has a livestock population of about 1139735 (Poultry), 2016823 (cattle), 942908 (Sheep), 288411(Goats), 74574(Horses), 49489(Donkeys) and 28371(Mules) [16].

\subsection{Study Animals}

Two groups of chickens based on management practice which included; 224(58.3\%) chickens under semi-intensive (reared on deep litter and backyard) and 160 (41.6\%) chickens under intensive management systems (reared on deep litter only)were sampled. The chickens' demographic characteristics (age, sex and breed) were also considered important. The age and breed of the study animals were determined by asking the owners following [17]. Those chickens 0 -6weeks of age were classifiedas chicks $(n=145), 7-15$ weeks of age as growers $(n=113)$ and those of the chickens greater than 16 weeks of age were categorized as adults $(\mathrm{n}=126)$ following [18]. $160(42.2 \%)$ male and 224 (57.8\%) female Chickens were sampled. Breed of the chickens was also another important factor considered and thus, about 110 Bovans brown and 274 Sasso T44 exotic chickens respectively were sampled.

\subsection{Study Design}

A cross-sectional study was undertaken from November 2017 to march 2018 on randomly selected exotic chickens from jimma town small scaleprivate poultry farms reared intensively and semiintensively. The study farms were selected based on breed, number, and permission of the owners, areas and management system. Chickens were selected by simple random sampling methods for inclusion into this study. The study included; sexes, two different breeds and chickens reared under semi-intensive and intensive management. 


\subsection{Sampling Method}

Multistage random sampling technique was employed to select farm chickens, so as to determine the prevalence of major gastrointestinal parasites of chickens and assess the potential risk factors for infection by employing simple floatation of faecal samples. Thus, farms in jimma town were grouped in to two groups (chickens kept under intensive farming) and (chickens kept under semi intensive farming).Then after, successive simple random sampling was undertaken to collect fecal samples.

\subsection{Sample Size Determination}

Since the prevalence of major GIT parasites of poultry in Jimma town small scale production system has not been reported, 50\% expected prevalence rate was used. In addition, 95\% confidenceinterval (CI) and 5\% desired absolute precision were also used following Thrusfield [19]. Therefore, the total sample was calculated using Thrusfield formula.

$$
\mathrm{n}=\frac{(1.96)^{2} \mathrm{P} \exp (1-\mathrm{Pexp})}{\mathrm{d}^{2}}
$$

Where, $\mathrm{n}=$ required sample size, $\mathrm{P}_{\exp }=$ expected prevalence and $\mathrm{d}=$ desired absolute precision

The expected prevalence of major GIT parasites of chickens is is $50 \%$ withthe required precision (d) of 5\% (0.05). By substituting thevalue in the above formula, we get the sample size:

$$
\frac{(1.96)^{2} * 0.5(1-0.5)}{(0.05)^{2}}=384
$$

\subsection{Sample Collection and Study Method}

Chickens fecalsamples were collected per cloaca using thermometer or swab where possible or witha spatula for upper part of freshly voided faeces.The faecal samples were placed into sampling bottles and labeled with farm name, identification number of the chicken, age, breed and sex appropriately, then placed in Ice box and transported to Jimma University College of Agriculture and Veterinary Medicine's parasitological Laboratory for processing.

The simple test tube flotation method of faecal samples was used for the detection of nematode and cestode eggs and Eimeriaoocysts in the faeces. It is based on the separating of eggs from faecal material and concentrating them by means of a flotation fluid. Sodium chloride solution was used as floating medium.Threegrams of fresh faeces were mixed thoroughly with $45 \mathrm{ml}$ concentrated sodium chloride solution in a beaker and later strained through a mesh screen. The strained faeces were poured immediately into test tubes and were placed in a test tube rack vertically while the retained faeces debris was discarded. In order to form a convex meniscus at the top of the test tubes, the tubes were topped up with the faecal suspension and a cover slips placed at the top for 20 minutes. The cover slips were lifted off straight up together with the flotation fluid that adhered to and were placed on a glass slide. The accumulated helminth eggs and coccidian oocysts under the cover slip were observed under a compound microscope for identification by $10 \mathrm{x}$ and $40 \mathrm{x}$ objective lens. The eggs and oocysts were identified on the basis of morphology and size of eggs [20].

\subsection{Statistical Analysis}

The data collected on the hard copy of sampling format were first entered in to Microsoft Excel work sheet version 2013 and analyzed using Statistical Package for Social Sciences (SPSS) software version 20. Descriptive and inferential statistics were utilized to summarize the data. Overall prevalence, prevalence of each parasite species, $\mathrm{p}$-value, chi square and odds ratio were calculated by SPSS. A 95\% confidence interval was used to describe statistical significance associations. Chisquare and p-value were used to test the statistical significance difference between the host risk factors in prevalence of major GIT parasites. Odds ratio was used to compare relative odds between two groups of each risk factors. The association is judged as significant when p- value is less than 0.05 and insignificant when greater than 0.05 .

\section{RESULT}

\subsection{Overall Prevalence}

A total of three hundred eighty four (384) exotic chickens, 224 from semi-intensive and 160 from intensive small scale commercial management systems were examined and out of which 160 (41.7\%) 
males and 224 (58.3\%) were females. The result of fecal examination showed that $292(76 \%)$ of the chickens were positive for one or another of the GIT parasite eggs and Eimeriaoocysts. From the positive results, 13 (3.39\%) were Cestodes of species Railletina cesticillus6 (1.56\%), Railletina echinobothrida 4 (1.04\%) and Davainea proglottina3 (0.78\%). 142 (36.97\%) were Nematodes species of Ascaridiagalli98 (25.5\%), Heterakis gallinarum 36 (9.4\%) and Capillaria species 5 (1.3\%). 115 (29.9\%) were Eimeria species, thus nematodes $(36.97 \%)$ were the most prevalent species followed by Eimeria species(29.9\%) and cestodes(3.39\%) were the least prevalent on overall prevalence. Among the Nematodes, the most prevalent species was A.galli (25.5\%) followed by H.gallinarum (9.4\%) and the least prevalent recorded was capillaria species (0.8\%). R.cesticillus $(1.56 \%)$ was found the most prevalent among Cestodes, whereas R.echinobothrida (1.04 \%) and D.proglottina $(0.78 \%)$ were recorded least prevalent respectively.

Table1. Overall prevalence of major GIT parasites among chickens $(N=384)$

\begin{tabular}{|l|l|l|}
\hline Species of GIT parasites & Number of positive birds and prevalence (\%) & $95 \%$ CI \\
\hline Nematodes & $142(36.97 \%)$ & $33-41 \%$ \\
\hline Ascaridia galli & $98(25.5)$ & \\
\hline Heterakis gallinarum & $36(9.4 \%)$ & \\
\hline Syngamus trachea & $5(1.3 \%)$ & \\
\hline Capillaria species & $3(0.8 \%)$ & \\
\hline Cestodes & $13(3.38 \%)$ & $1.5-5 \%$ \\
\hline Railletina cesticillus & $6(1.56 \%)$ & \\
\hline Railletina echinobothrida & $4(1.04 \%)$ & \\
\hline Davainea proglotina & $3(0.78 \%)$ & \\
\hline Eimeria species & $115(29.9 \%)$ & $25 \%-34.5 \%$ \\
\hline Mixed infection & $22(5.7 \%)$ & \\
\hline Total & $292(76 \%)$ & \\
\hline
\end{tabular}

\subsection{Prevalence of Mixed Infections}

Of the total of 384 chickens examined for the presence of major GIT parasites, mixed infections were also detected and about $22(5.7 \%)$ of the chickens were recorded to harbor double mixed infection due to A.galli and Eimeria species 9(2.34\%), H.gallinarum and Eimeriaspecies 5(1.3\%), R.cesticillus and Eimeria species 4(1.04\%), A.galli and H.gallinarum 3(0.78\%), S. trachea and Eimeria species $1(0.26 \%)$. There was no triple mixed infection detected.

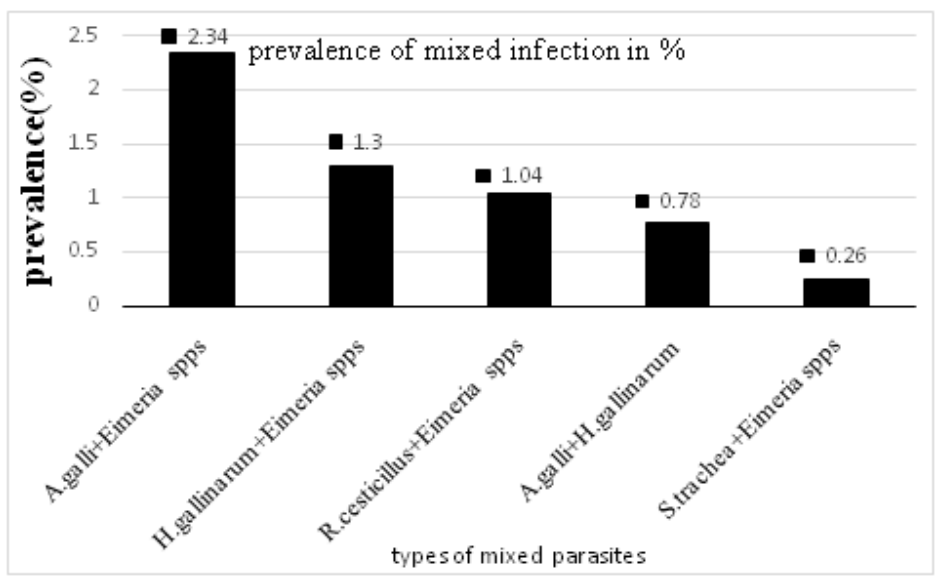

$\mathrm{N}=384$

Figure1. Prevalence of mixed infections.

\subsection{Prevalence between Sexes}

Out of 160 male and 224 female chickens examined for the presence of eggs of different GIT helminthes and Eimeriaoocysts , 121(75.62\%)and 171(76.34\%) males and females respectively were found infected by one or another of the GIT parasites identified.Statistical analysis of data showedpvalue of $0.872,0.026$ chi square value and 1.04 odds ratio (male/female). Although overall prevalence was higher in females than males, it was statistically insignificant $(\mathrm{P}>0.05)$ But,female chickens had 1.04 times more odds of harboring major GIT parasites than the male ones. Female chickens harboring nematodes had odds of 1.771 times greater than male ones and had p-value of 0.009 and 
Prevalence of Major Gastrointestinal Parasites in Small Scale Commercial Poultry Farms from Jimma Town, Southwest Ethiopia

4.214 chi square value and thus, the difference between sexes harboring major GIT parasites were statistically significant $(\mathrm{p}<0.05)$. Cestodes and mixed infection had 0.812 and $0.27 \mathrm{p}$-value respectively, thus there was no statistical significance between sexes ( $p$-value $>0.05$ ) for harboring cestodes and mixed double infection. p-value of difference in sexes for harboring Eimeria species was 0.04( $<<0.05)$, thus there was statistical significance between sexes harboring Eimeria species. Odds of male chickens harboring Eimeria species were 0.631 times less than that of female ones.

Table2. Prevalence of major GIT parasites among chickens between sexes

\begin{tabular}{|c|c|c|c|c|c|c|}
\hline $\begin{array}{l}\text { Gastrointestinal } \\
\text { parasites }\end{array}$ & Number of pos & $\begin{array}{c}\text { birds and prevale } \\
(\%)\end{array}$ & $\mathrm{n}$ both sexes & & & \\
\hline & Male $(\mathrm{N}=160)$ & Female(N=224) & total & $\chi^{2}$ & p-value & OR \\
\hline Eimeriaspps & $57(35.6 \%)$ & $58(25.9 \%)$ & $115(29.9 \%)$ & 4.214 & 0.040 & 0.631 \\
\hline Nematodes & $47(29.4 \%)$ & $95(42.4 \%)$ & $142(37 \%)$ & 6.806 & 0.009 & 1.771 \\
\hline A.galli & $29(18.1 \%)$ & $69(30.8 \%)$ & $98(25.5 \%)$ & 7.893 & 0.005 & 2.011 \\
\hline H.gallinarum & $11(6.9 \%)$ & $25(11.2 \%)$ & $36(9.4 \%)$ & 2.018 & 0.155 & 1.702 \\
\hline S.trachea & $0(0 \%)$ & $5(2.2 \%)$ & $5(1.3 \%)$ & 3.619 & 0.057 & 1.023 \\
\hline Capillariaspps & $1(0.6 \%)$ & $2(0.9 \%)$ & $3(0.8 \%)$ & 0.086 & 0.769 & 1.432 \\
\hline cestodes & $5(3.1 \%)$ & $8(3.6 \%)$ & $13(3.4 \%)$ & 0.057 & 0.812 & 1.148 \\
\hline Railletinaspps & $3(1.9 \%)$ & $7(3.1 \%)$ & $10(2.6 \%)$ & 0.575 & 0.448 & 1.688 \\
\hline D.proglottina & $2(1.2 \%)$ & $1(0.4 \%)$ & $3(0.8 \%)$ & 0.778 & 0.378 & 0.354 \\
\hline $\begin{array}{c}\text { Mixed } \\
\text { infection }\end{array}$ & $12(7.5 \%)$ & $10(4.5 \%)$ & $22(5.7 \%)$ & 1.593 & 0.207 & 0.576 \\
\hline overall & $121(75.62 \%)$ & $171(76.34 \%)$ & $292(76 \%)$ & 0.026 & 0.872 & 1.04 \\
\hline
\end{tabular}

\subsection{Prevalence among Different Age Groups}

In the study, the overall prevalence $(62.1 \%$ in chicks, $83.3 \%$ in growers and $85.6 \%$ in adults) was recorded. Overall prevalence in chicks were lower than that of adults and growers and adults had the highest prevalence followed by growers. Chickens within the age group of $>16$ weeks (adults) were highly significantly $(\mathrm{P}<0.05)$ infected than the chickens with age groups of $0-6$ weeks (chicks) and although most prevalent in adults, there was no statistical significance $(\mathrm{P}>0.05)$ with age groups of 7 15 weeks (growers). higher prevalence in adults and growers $(56 \%, 43.8 \%)$ than in chicks $(15.17 \%)$ for nematodes infections were recorded and the differences were statistically highly significant $(\mathrm{P}<0.05)$ between the age groups; but the prevalence of Eimeria species was found higher in chicks $(42.1 \%)$ than in growers $(28.6 \%)$ and adults $(17.6 \%)$ with a statistically significant $(\mathrm{P}<0.05)$ difference of the prevalence between age groups. cestodes were not prevalent in chicks $(0 \%)$, but most prevalent in adults $(8 \%)$ followed by growers $(2.7 \%)$. The difference in prevalence of cestodes between age groups where statistically highly significant $(\mathrm{p}<0.05)$. Prevalence of double mixed infection were most prevalent in growers than chicks (4.8\%) and adults (4\%) but, it was statistically insignificant $(\mathrm{p}>0.05)$.

Table3. Prevalence of major gastrointestinal parasites among age groups

\begin{tabular}{|c|c|c|c|c|c|}
\hline $\begin{array}{c}\text { Gastrointestinal } \\
\text { parasites }\end{array}$ & \multicolumn{3}{|c|}{ Number of positive birds and prevalence in different } & & \\
\hline & $\begin{array}{c}\text { chiks(N=145) } \\
0-6 \text { weeks }\end{array}$ & $\begin{array}{c}\text { Growers } \\
(\mathrm{N}=114) \\
7-15 \mathrm{wks}\end{array}$ & $\begin{array}{c}\text { Adults (N=125) } \\
>16 \mathrm{wks}\end{array}$ & $\chi 2$ & $\mathrm{p}$-value \\
\hline Eimeriaspps & $61(42.1 \%)$ & $32(28.1 \%)$ & $22(17.6 \%)$ & 19.431 & 0.000 \\
\hline Nematodes & $22(15.17 \%)$ & $50(43.8 \%)$ & $70(56 \%)$ & 51.309 & 0.000 \\
\hline A.galli & $12(8.2 \%)$ & $38(33.3 \%)$ & $48(38.4 \%)$ & 37.255 & 0.000 \\
\hline H.gallinarum & $10(6.9 \%)$ & $10(8.7 \%)$ & $16(12.8 \%)$ & 1.249 & 0.535 \\
\hline S.trachea & $0(0 \%)$ & $2(1.8 \%)$ & $3(2.4 \%)$ & 3.267 & 0.195 \\
\hline Capillariaspps & $0(0 \%)$ & $0(0 \%)$ & $3(2.4 \%)$ & 6.265 & 0.044 \\
\hline cestodes & $0(\%)$ & $3(2.7 \%)$ & $10(8 \%)$ & 13.417 & 0.001 \\
\hline Railletinaspps & $0(0 \%)$ & $2(1.8 \%)$ & $8(6.4 \%)$ & 11.303 & 0.004 \\
\hline D.proglottina & $0(0 \%)$ & $1(0.9 \%)$ & $2(1.6 \%)$ & 2.236 & 0.327 \\
\hline Mixed infection & $7(4.8 \%)$ & $10(8.8 \%)$ & $5(4 \%)$ & 2.864 & 0.239 \\
\hline Total Prev.(\%) & $90(62.1 \%)$ & $95(83.3 \%)$ & $107(85.6 \%)$ & 25.134 & 0.000 \\
\hline
\end{tabular}


Prevalence of Major Gastrointestinal Parasites in Small Scale Commercial Poultry Farms from Jimma Town, Southwest Ethiopia

\subsection{Prevalence Difference between Breeds}

A total of 110 bovans and 274 sasso $\mathrm{T} 44$ exotic breeds of chickens were examined for major GIT parasites out of which $86(78.2 \%)$ and $206(75.2 \%)$ of the bovans and sasso $\mathrm{T} 44$ chickens respectively were found to host one or more of the different GIT parasites and the difference in the overall prevalence was statistically insignificant $(\mathrm{P}>0.05)$ between breeds. Overall odds of bovans breed to harbor major GIT parasites was 1.183 times greater than sasso t 44 breed. Prevalence of Eimeria species was greater in sasso t $44(32.8 \%)$ than bovans breed $(22.7 \%)$. Nematodes had greater prevalence in bovans $(41.8 \%)$ than sasso t 44 breed $(36 \%)$, it was statistically insignificant (p>0.05) and bovans had 1.333 times greater odds of harboring nematodes than sasso $t 44$. Cestodes was more prevalent in Bovansbrown (7.3\%) than Sasso T 44 breed (1.8\%), it was statistically highly significant $(\mathrm{p}<0.05)$ and had odds of harboring major GIT parasites 4.22 times greater than Sasso T 44.

Table4. Prevalence of major gastrointestinal parasites among chickens between breeds

\begin{tabular}{|c|c|c|c|c|c|c|}
\hline Gastrointestinal parasites & \multicolumn{2}{|c|}{$\begin{array}{c}\text { Number of positive birds and prevalence in } \\
\text { different breeds (\%) }\end{array}$} & & & \\
& $\begin{array}{c}\text { Sasso } \\
\text { T44(n=274) }\end{array}$ & Bovans(n=110) & total & $\chi 2$ & p-value & OR \\
\hline Eimeriaspecies(protozoa) & $90(32.8 \%)$ & $25(22.7 \%)$ & $115(29.4 \%)$ & 3.831 & 0.05 & 0.601 \\
\hline Nematodes & $96(36 \%)$ & $46(41.8 \%)$ & $142(37 \%)$ & 1.549 & 0.213 & 1.333 \\
\hline A.galli & $69(25.2 \%)$ & $29(26.4 \%)$ & $98(25.5 \%)$ & 0.058 & 0.810 & 1.064 \\
\hline H.gallinarum & $20(7.3 \%)$ & $16(14.5 \%)$ & $36(9.4 \%)$ & 4.851 & 0.028 & 2.162 \\
\hline S.trachea & $5(1.8 \%)$ & $0(0 \%)$ & $5(1.3 \%)$ & 2.034 & 0.154 & ------ \\
\hline Capillariaspps & $1(0.4 \%)$ & $2(1.8 \%)$ & $3(0,8 \%)$ & 2.138 & 0.144 & 5.056 \\
\hline cestodes & $5(1.8 \%)$ & $8(7.3 \%)$ & $13(3.4 \%)$ & 7.122 & 0.008 & 4.22 \\
\hline Railletinaspps & $4(1.5 \%)$ & $6(5.5 \%)$ & $10(2.6 \%)$ & 4.938 & 0.026 & 3.894 \\
\hline D.proglottina & $1(0.4 \%)$ & $2(1.8 \%)$ & $3(0.8 \%)$ & 2.138 & 0.144 & 5.056 \\
\hline Mixed infection & $15(5.5 \%)$ & $7(6.4 \%)$ & $22(5.7 \%)$ & 0.115 & 0.735 & 1.173 \\
\hline Total & $206(75.2 \%)$ & $86(78.2 \%)$ & $292(76 \%)$ & 0.388 & 0.534 & 1.183 \\
\hline
\end{tabular}

\subsection{Prevalence among Chickens between Management Systems}

Of the 224 and 160 chickens examined from semi-intensive and intensive small scale commercial management systems respectively, overall prevalence of $80.3 \%$ in semi-intensively and $70 \%$ in intensively reared chickens were recorded and the difference in prevalence of major GIT parasites was statistically significant $(\mathrm{P}<0.05)$ between the management systems. Intensively reared chickens had odds of 0.57 times less than semi-intensively reared ones for harboring major GIT parasites. Eimeria species was highly prevalent in Intensive management $(34.4 \%)$ than semi-intensive one $(26.8 \%)$ and had 1.432 times odds of harboring major GIT parasites. But, nematodes were highly prevalent in semi-intensive (42.9\%) management than intensive ones $(28.8 \%)$, it was statistically significant and intensive management had 0.538 times less odds of harboring major GIT parasites than semiintensive. Cestodes were highly more prevalent in semi-intensive management (5.4\%) than intensive management $(0.6 \%)$, it was highly significant $(\mathrm{p}<0.05)$ and intensive management had 0.111 times less odds of harboring major GIT parasites than semi-intensive.

Table5. Prevalence among chickens between Management systems

\begin{tabular}{|c|c|c|c|c|c|c|}
\hline $\begin{array}{c}\text { Gastrointestinal } \\
\text { parasites }\end{array}$ & \multicolumn{2}{|c|}{$\begin{array}{c}\text { Number of positive birds and prevalence in } \\
\text { different management systems }(\%)\end{array}$} & & & \\
\hline & $\begin{array}{c}\text { Semi-intensive } \\
(\mathrm{n}=224)\end{array}$ & $\begin{array}{c}\text { Intensive } \\
\mathrm{N}=160\end{array}$ & Total(N=384) & $\chi 2$ & $\mathrm{p}$-value & OR \\
\hline Eimeriaspecies & $60(26.8 \%)$ & $55(34.4 \%)$ & $115(29.9 \%)$ & 2.562 & 0.109 & 1.432 \\
\hline Nematodes & $96(42.9 \%)$ & $46(28.8 \%)$ & $142(37 \%)$ & 7.97 & 0.005 & 0.538 \\
\hline A.galli & $57(25.4 \%)$ & $41(25.6 \%)$ & $98(25.5 \%)$ & 0.002 & 0.968 & 1.009 \\
\hline H.gallinarum & $33(14.7 \%)$ & $3(1.9 \%)$ & $36(9.4 \%)$ & 18.160 & 0.000 & 0.111 \\
\hline S.trachea & $5(2.2 \%)$ & $0(0 \%)$ & $5(1.3 \%)$ & 3.619 & 0.057 & ------- \\
\hline Capillariaspps & $3(1.3 \%)$ & $0(0 \%)$ & $3(0.8 \%)$ & 2.160 & 0.142 & ----- \\
\hline cestodes & $12(5.4 \%)$ & $1(0.6 \%)$ & $13(3.4 \%)$ & 6.390 & 0.011 & 0.111 \\
\hline Railletinaspps & $9(4 \%)$ & $1(0.6 \%)$ & $10(2.6 \%)$ & 4.236 & 0.040 & 0.150 \\
\hline D.proglottina & $3(1.3 \%)$ & $0(0 \%)$ & $3(0.8 \%)$ & 2.160 & 0.142 & ----- \\
\hline
\end{tabular}

International Journal of Research Studies in Biosciences (IJRSB) 
Prevalence of Major Gastrointestinal Parasites in Small Scale Commercial Poultry Farms from Jimma Town, Southwest Ethiopia

\begin{tabular}{|c|c|c|c|c|c|c|}
\hline Mixed infection & $12(5.4 \%)$ & $10(6.2 \%)$ & $22(5.7 \%)$ & 0.138 & 0.711 & 1.178 \\
\hline Total prevalence & $180(80.3 \%)$ & $112(70 \%)$ & $292(76 \%)$ & 5.496 & 0.019 & 0.57 \\
\hline
\end{tabular}

\section{DISCUSSION}

The overall prevalence of GIT parasites among chickens in this study (76\%) was higher than the report (46.67\%) from Anand district India [21]. But, it was found to be in line with a report (79.9\%) from Bahirdar town in small scale commercial production system, Ethiopia [22].The difference in the prevalence of GIT parasitism could be explained by the differences in geographical location, breed, seasonal variation, management and biosecurity, sample size, Veterinary facilitiesand public awareness to diseases.

The prevalence of Nematodes in this study (36.97\%) was found to be lower than a report (46.9\%) fromin and around Bahirdartown of Ethiopia [23]. Differences in management systems of chickens, breed of chickens considered in the studies and health care service may be responsible for the variation in prevalence of Nematodes among chickens in this study and studies carried out at different areas.

The prevalence of Cestodes in the present study (3.38\%) was found to be comparable to the previous study (1.56\%) from HaromayaWoreda, South Eastern Ethiopia [24]. The prevalence of Eimeriaspecies among chickens (29.9\%) confirmed in this study agrees with the findings in central Ethiopia.

In this study, statistically significant $(\mathrm{P}<0.05)$ differences in the overall prevalence of GIT parasitism of chickens between age groups and management systems were confirmed with the overall prevalence higher in adults $(85.6 \%)$ and growers $(83.3 \%)$ than chicks $(62.1 \%)$ and semi-intensive $(80.3 \%)$ than intensive $(70 \%)$. This result was in congruent with the result of previous reports from Haromayaworeda [25]. But the overall prevalence was found to be insignificant $(\mathrm{P}>0.05)$ between breed and sex groups. This agrees with the finding of Beyene [17]. There was a significant difference $(\mathrm{P}<0.05)$ in the prevalence of Eimeria species between the different age and sex groups. The higher infection prevalence of Eimeria species was observed in the young, intensive than in adult aged semi-intensive management. This agrees with findings in Bahirdar town, Ethiopia [9]. Generally the disparity in the result of the present and earlier works in other areas might be due to the variation among the geographical location of theresearch area, method of study, sample size, breed differences, seasonal variations, managemental practices, biosecurity, ecological conditions of the study area and anthelmintic treatment.

\section{CONCLUSION AND RECOMMENDATION}

Nematodes, cestodes and Eimeria species are the major gastrointestinal parasites of poultry identified. Despite, small scale commercial production system reduces parasitic disease burden, this study revealed a high prevalence of major gastrointestinal parasites of chickens in jimma town small scale commercial poultry farms. Sex, age, breed and management systems were identified to be important risk factors in the prevalence of gastro intesinal parasites of poultry in the study area. High overall prevalence was scored in semi-intensive than intensive management system and adults and growers than chicks. Eimeria species were proofed to occur more in intensive management system and chicks. Based on the above conclusion the following recommendations were forwarded:

- Intensive management with good management system should be practiced in small scale production system to lower the burden of gastrointestinal parasites.

- Strategic deworming using anthelminthic and anticoccidial drugs should be used appropriately to lower the burden.

- Government institutions should be involved in improving awareness of the poultry disease prevention methods to local people.

- Further researches should be conducted to assess the impact of major gastrointestinal parasites on health and production performance of chickens including cost effectiveness of control strategies. 


\section{REFERENCES}

[1] Banerjee, G.C, A text book of animal husbandry. 8 ed. Delhi: Oxford and IBH publishing Co,2005, pp. 837.

[2] Ethiopian Agricultural research organization, (EARO),National poultry research program : Strategydocument, Addis Ababa, Ethiopia, 1999.

[3] Nnadi, P. A., and S. O. George. "A cross-sectional survey on parasites of chickens in selected villages in the subhumid zones of South-Eastern Nigeria." Journal of parasitology research 2010 (2010).

[4] Bush, J. "The threat of avian flu predicted impacts on rural livelihoods in Southern Nation, Nationalities and Peoples Region (SNNPR), Ethiopia." The Food Economy Group(2006).

[5] Molla, Meseret. "Characterization of village chicken production and marketing system in gommawereda, jimma zone, Ethiopia." Msc diss., Jimma University, 2010.

[6] Kenea,Tigist, JemereBekele, and DesieSheferaw. "Gastro-intestinal nematodes of sheep and goats in three districts of Kaffa and Bench Maji Zones, Southwest Ethiopia." Ethiopian Veterinary Journal 19, no. 2 (2015): 67-76.

[7] Moges, Fisseha, AberaMellesse, and TadelleDessie. "Assessment of village chicken production system and evaluation of the productive and reproductive performance of local chicken ecotype in Bure district, North West Ethiopia." (2010).

[8] Puttalakshmamma, G. C., K. J. Ananda, P. R. Prathiush, G. S. Mamatha, and Suguna Rao. "Prevalence of Gastrointestinal parasites of Poultry in and around Banglore." Veterinary World 1, no. 7 (2008).

[9] Belete, A. and Addis, M., Survey of Gastrointestinal Helminthes among Chickens in Bahir Dar Town, Ethiopia, European Journal of Applied Sciences 7 (2): 64-71, (2015).

[10] Demis, C., Anteneh, M. and Basith, A., Tapeworms of Poultry in Ethiopia: A Review. British Journal of Poultry Sciences, 4(3), pp.44-52, (2015).

[11] Beyene, Kessewdeg, BasaznewBogale, and MershaChanie. "Study on effects and occurrence of nematodes in local and exotic chickens in and around Bahir Dar, Northwest Ethiopia." American-Eurasian Journal of Science Research 9, 62-66, (2014).

[12] Negash, Alemayehu, Abdu Mohamed, and KalkidanWondimu. "Study on prevalence and risk factors associated with poultry Coccidiosis in and around Hawassa Town, South Ethiopia." British Journal of Poultry Sciences 4, no. 2, 34-43, (2015).

[13] Obasi, O. L., O. J. Ifut, and E. A. Offiong. "An outbreak of caecalcoccidiosis in a broiler flock post Newcastle disease vaccination." Journal of Animal and Veterinary Advances5(12),1239-1241, (2006).

[14] GazaliAbafajifar,Assesment of poultry productionconstraints and evaluation of different concentrate on production performance and parasitic burden of exotic chickens in kersadistrict of Jimmazone,Msc thesis, Jimma university, Jimma,Ethiopia, pp79, (2017).

[15] Shiferaw, S., F. Tamiru, A. Gizaw, D. Atalel, W. Terfa, M. Dandecha, and A. Mekibib. "Study on prevalence of helminthes of local backyard and exotic chickens in and around ambowestshoa zone, Oromia regional state, Ethiopia." J. Vet. Sci. Med 4, no. 2 (2016): 4.

[16] CSA, 2012. Agricultural Sample Survey. Report On Livestock and Livestock Characteristics (Private Peasant Holdings): Addis Ababa Volume Statistical Bulletin, 2: 532.

[17] Beyene, Kessewdeg, BasaznewBogale, and MershaChanie. "Study on effects and occurrence of nematodes in local and exotic chickens in and around Bahir Dar, Northwest Ethiopia." American-Eurasian Journal of Science Research 9, 62-66, (2014).

[18] Jegede, O. C., I. A. Asadu, M. Opara, S. S. Obeta, and D. O. Olayemi. "Gastrointestinal parasitism in local and exotic breeds of chickens reared in Gwagwalada Guinea Savannah zone of Nigeria." Sokoto Journal of Veterinary Sciences 13, no. 3 ,25-30, (2015).

[19] Thrusfield, Michael. Veterinary epidemiology. 3rd edition ,John Wiley \& Sons, 2006.

[20] Urquhart,G.M.,J.Armour,J.L.Dunncan,andF.W. Jennings. "Veterinary Parasitology, ELBS."(1996):,pp307.

[21] Gupta, Yogesh Kumar. "Studies on Gastro-Intestinal Parasites Of Poultry in Anand District." PhD diss., Anand Agricultural University, Anand, 2012.

[22] Molla, W., H. Haile, G. Almaw, and W. Temesgen. "Gastrointestinal helminths of local backyard chickens in North Gondar Administrative Zone, Ethiopia." Revue de Médecine Vétérinaire 163, no. 7, 362-367, (2012).

[23] Beyene, Kessewdeg, BasaznewBogale, and MershaChanie. "Study on effects and occurrence of nematodes in local and exotic chickens in and around Bahir Dar, Northwest Ethiopia." American-Eurasian Journal of Science Research 9, 62-66, (2014). 
Prevalence of Major Gastrointestinal Parasites in Small Scale Commercial Poultry Farms from Jimma Town, Southwest Ethiopia

[24] Tesfaheywet, Z., E. Amare, and Z. Hailu. "Helminthosis of chickens in selected small scale commercial poultry farms in and around HaramayaWoreda, Southeastern Ethiopia." Journalof Veterinary Advances 2, no. 9 (2012): 462-468.

[25] Ashenafi, H., and Y. Eshetu. "Study on gastrointestinal helminths of local chickens in central Ethiopia." Revue de médecinevétérinaire 155 (2004): 504-507.

\section{AbBreviations}

OR

Odds Ratio

CSA

GIT

CI Confidence Interval

$\chi^{2} \quad$ Chi square

EARO

Gastrointestinal
Central Statistical Agency

SPSS Statistical Package for Social Sciences

Citation: Waktole Yadeta, et.al, "Prevalence of Major Gastrointestinal Parasites in Small Scale Commercial Poultry Farms from Jimma Town, Southwest Ethiopia”. International Journal of Research Studies in Biosciences (IJRSB). 7(10), pp. 13-21. DOI: http://dx.doi.org/10.20431/2349-4050.0710002

Copyright: (c) 2019 Authors This is an open-access article distributed under the terms of the Creative Commons Attribution License, which permits unrestricted use, distribution, and reproduction in any medium, provided the original author and source are credited. 